\title{
¿Qué perturba el sueño?
}

\section{What disturbs sleep?}

El tema es tan amplio que puede ocupar fácilmente un tratado entero. Aunque el dormir sea un estado al que accedemos con regularidad cotidiana, requiere de un complejo equilibrio de diversos factores, psíquicos, somáticos y ambientales. ¿Qué nos quita el sueño a los peruanos? En un mundo con fronteras más permeables, podemos afirmar que se trata de lo mismo que sucede en el resto del planeta. Pero quizá haya algunas particularidades locales: los problemas respiratorios (especialmente en Lima y otras ciudades con elevada humedad); los ruidos nocturnos de vecinos o vehículos, expresión de un país con aún escasa conciencia cívica; y por cierto las dificultades económicas, aunque nuevamente aquí no estamos solos. Por supuesto existen también diversos problemas somáticos cuyo tratamiento resuelve o alivia el insomnio y, en la esfera psicológica, las razones personales más diversas que impiden el descanso nocturno, como los "problemas de conciencia" y otros conflictos emocionales.

Dormir mal genera diversos trastornos. En este número presentamos una investigación realizada por el Instituto del Sueño, ampliamente sustentada, en la que se establece una relación significativa entre trastornos del sueño, la somnolencia al despertar y dolores físicos variados. Además el neurólogo Armando Filomeno revisa la historia del síndrome de Asperger en un ilustrado artículo en el que sigue la pista al origen clínico del diagnóstico y vicisitudes bibliográficas de su denominación, así como las complicaciones que pueden surgir con la nueva clasificación de enfermedades mentales. Dos interesantes casos clínicos, ambos de pacientes de mediana edad, son presentados. El primero de ellos, un caso de adicción a biperideno en un paciente psicótico, es especialmente interesante por el diagnóstico diferencial con el síndrome neuroléptico maligno. El otro, un paciente con un insulinoma, muestra el drama y consecuencias de un diagnóstico tardío.

Por último, el reciente libro del chileno Enrique Jadresic (Blushing; cuando sonrojarse duele), quien visitará Lima en junio de 2012, y que trata sobre el rubor facial patológico es revisado por Marta Rondón.

Les deseamos una buena lectura.

Eduardo Gastelumendi ${ }^{1}$

${ }^{1}$ Co-Editor en Jefe de la Revista de Neuro-Psiquiatria. 